\title{
Nephronophthisis
}

\section{Report of 8 Cases from Britain}

\author{
A. A. M. GIBSON and G. C. ARNEIL \\ From the Department of Pathology, Royal Hospital for Sick Children, Glasgow and the Department of Child Health, \\ University of Glasgow
}

Gibson, A. A. M., and Arneil, G. C. (1972). Archives of Disease in Childhood, 47, 84. Nephronophthisis: report of 8 cases from Britain. Eight Scottish children with nephronophthisis are described. The typical clinical picture is thirst and polyuria associated with severe anaemia, progressive impairment of renal function, and dwarfism. Isosthenuria and gross enlargement of the bladder are usually present. Systemic hypertension is usually absent until the terminal stages.

Five of these children are dead and the kidneys have been examined at necropsy. Percutaneous renal biopsy has been carried out on the remainder. The typical morbid anatomical feature is the presence of medullary cysts in small uniformly contracted kidneys. Histologically, the kidney is diffusely affected with extensive sclerosis of glomeruli, periglomerular fibrosis, and obvious hyaline thickening of the tubular basement membrane.

The disease progresses inexorably and renal transplantation offers the only longterm solution.

'Die familiäre Juvenile Nephronophthise' described by Fanconi $e t$ al. in 1951 was soon recognized in several European countries (Enell, 1952; Hackzell, 1952; Hooft, Roels, and Herpol, 1959; Broberger, Winberg, and Zetterström, 1960; Royer, Mathieu, and Habib, 1963). Apart from the family reported from Ireland in 1970 (Alexander and Campbell), the condition has received little attention in the United Kingdom.

During the period 1934-1970, 8 children with clinical and histological evidence of nephronophthisis have been investigated at this hospital; details of these children are given in Tables I-IV.

This series of 8 children included 2 sibships. There were a sister and brother (Cases 7 and 8 ) and 2 sisters (Cases 3 and 4). The remaining 4 children had a total of 10 healthy sibs. The age of recognized onset of the disease varied from $3 \frac{1}{2}$ to 11 years. Death occurred at the age of 10 or 11 years in the 5 fatal cases. 3 children, aged 10,12, and 17 years, are still alive but in progressive renal failure.

\section{Presenting Features}

Thirst and polyuria were the presenting features in 7 of the 8 children. Hb ranged from $6 \cdot 8 \mathrm{~g}-10.0 \mathrm{~g} /$ $100 \mathrm{ml}$ in the 7 children for whom this value was recorded on first attendance. Each of the 8 affected children was dwarfed, some severely. The bladder size was

Received 23 June 1971. noted to be large on first attendance in 4 of the 5 children for whom this observation was recorded. Systemic hypertension was noted in only 1 child on first attendance at hospital $(150 / 105 \mathrm{mmHg}$ in Case 6); the remainder were normotensive. 4 of the 8 children had reverted to enuresis nocturnally.

The urinary and biochemical findings on first admission to hospital are recorded in Table II.

The paucity of red cells, leucocytes, and casts in the urine is a striking feature. The pattern of high urinary output of low specific gravity, poor urea concentration, and progressively poorer corrected creatinine clearance is reflected in the abnormal biochemical findings in the serum. There was clear evidence of azotaemia on presentation with hypokalaemia in 3 patients and hypocalcaemia in 1. The level of serum sodium was almost normal. With progression of the disease, the hypocalcaemia tended to increase and to produce radiological changes as shown in Table III.

This constant renal osteodystrophy of varying severity is non-specific and presumably due to secondary hyperparathyroidism. Radiological investigation confirmed the very large bladder in each child in whom it had been detected clinically, while infusion urography showed poor concentration of dye due to poor renal function.

\section{Pathology}

Necropsy was carried out in all 5 children who died. The kidneys in every case were less than half of the normal size but the rewas no difference between the two sides. The external surface was uniformly granular and finely scarred with an adherent capsule. Loss of 
TABLE I

Sex, Age at Onset, Diagnosis, and Death; and Number of Sibs of 8 Children with Nephronophthisis

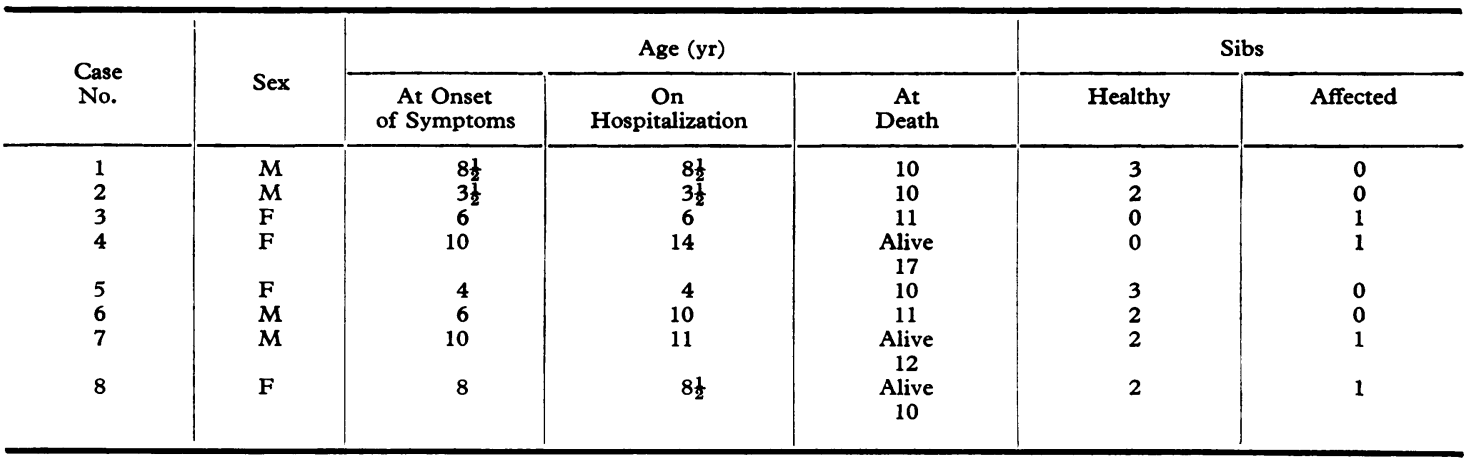

TABLE II

Urinary and Biochemical Findings

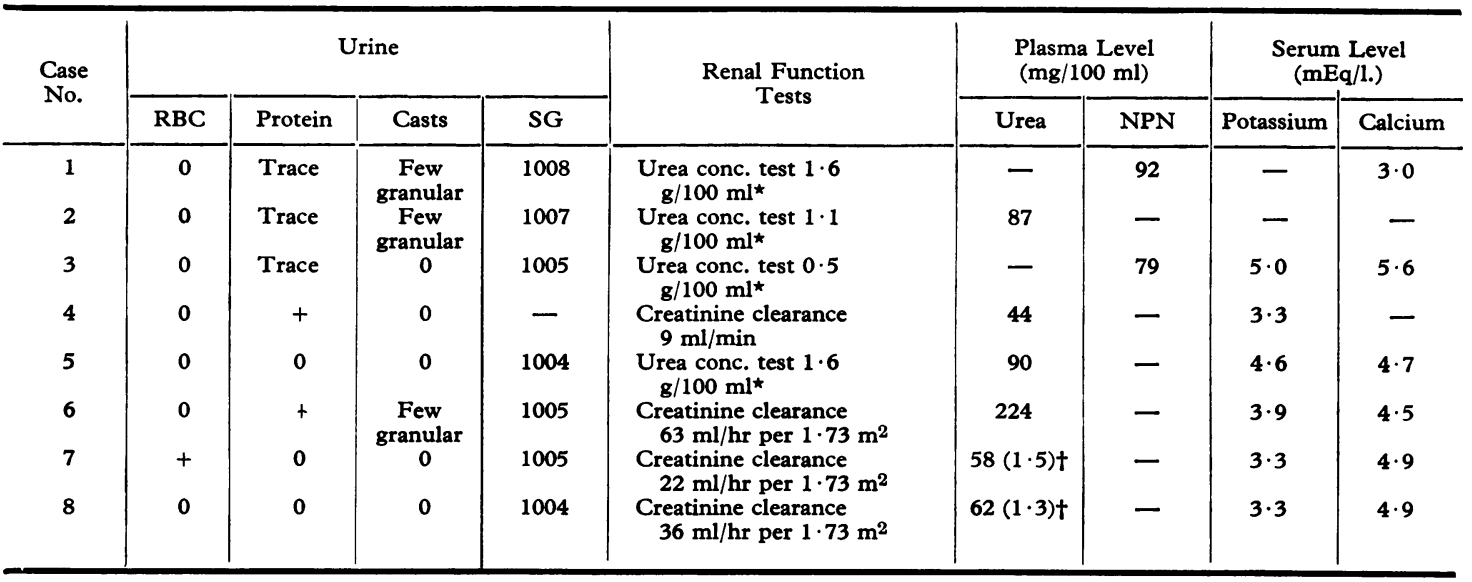

RBC, red blood corpuscles; SG, maximum specific gravity; NPN, non-protein nitrogen.

*Maclean and de Wesselow's method.

tFigures in parentheses are serum creatinine levels $(\mathrm{mg} / 100 \mathrm{ml})$.

TABLE III

Radiological Findings

\begin{tabular}{|c|c|c|}
\hline Case No. & Excretion Urography & Other Examination \\
\hline $\begin{array}{l}1 \\
2 \\
3 \\
4\end{array}$ & $\begin{array}{l}\text { Unsuccessful } \\
\text { Not done } \\
\text { Not done } \\
\text { Two small kidneys with smooth outline }\end{array}$ & $\begin{array}{l}\text { Renal osteodystrophy terminally } \\
\text { Renal osteodystrophy terminally } \\
\text { Renal osteodystrophy terminally } \\
\text { Micturating cystograph shows no vesicoureteric reflux; } \\
\text { renal osteodystrophy present }\end{array}$ \\
\hline 5 & $\begin{array}{l}\text { Both kidneys small and smooth; gross impairment of } \\
\text { function }\end{array}$ & Renal osteodystrophy present \\
\hline 7 & $\begin{array}{l}\text { Both kidneys small; very poor renal function; slight } \\
\text { irregularity of outline }\end{array}$ & Renal osteodystrophy present \\
\hline 8 & $\begin{array}{l}\text { Both kidneys smooth and of average size, very poor } \\
\text { renal function }\end{array}$ & Renal osteodystrophy present \\
\hline
\end{tabular}


TABLE IV

Pathological Features

\begin{tabular}{|c|c|c|c|c|c|c|c|}
\hline \multirow{3}{*}{$\begin{array}{l}\text { Case } \\
\text { No. }\end{array}$} & \multirow{3}{*}{$\begin{array}{c}\text { Age } \\
\text { at } \\
\text { Death } \\
\text { (yr) }\end{array}$} & \multirow{3}{*}{$\begin{array}{l}\text { Source } \\
\text { of Tissue }\end{array}$} & \multicolumn{4}{|c|}{ Findings in Kidney } & \multirow{3}{*}{ Other Findings } \\
\hline & & & \multicolumn{2}{|c|}{$\begin{array}{l}\text { Weight } \\
\text { (g) }\end{array}$} & \multirow{2}{*}{$\begin{array}{l}\text { Medullary } \\
\text { Cysts }\end{array}$} & \multirow{2}{*}{$\begin{array}{c}\text { Tubular } \\
\text { Basement } \\
\text { Membrane } \\
\text { Thickening }\end{array}$} & \\
\hline & & & Right & Left & & & \\
\hline 1 & 10 & Necropsy & 37 & 43 & + & +++ & Left ventricular hypertrophy \\
\hline 2 & 10 & Necropsy & - & - & + & +++ & Left ventricular hypertrophy \\
\hline 3 & 11 & Necropsy & 20 & 22 & + & +++ & $\begin{array}{l}\text { Petechial haemorrhage; pulmonary oedema; } \\
\text { left ventricular hypertrophy }\end{array}$ \\
\hline 4 & - & Biopsy & - & - & 一 & + & - \\
\hline 5 & 10 & Necropsy & 37 & 35 & + & +++ & Necropsy restricted \\
\hline 6 & 11 & Necropsy & 44 & 34 & + & +++ & $\begin{array}{l}\text { Left ventricular hypertrophy; pulmonary } \\
\text { odema }\end{array}$ \\
\hline $\begin{array}{l}7 \\
8\end{array}$ & - & $\begin{array}{l}\text { Biopsy } \\
\text { Biopsy }\end{array}$ & - & - & 二 & $\begin{array}{l}+ \\
+\end{array}$ & - \\
\hline
\end{tabular}

the normal corticomedullary markings and small medullary cysts up to $8 \mathrm{~mm}$ in diameter were constant features of the cut surface (Fig. 1). The histological changes were similar in each case and noticeably diffuse in distribution. In the cortex there was extensive sclerosis of glomeruli and hypertrophy of surviving glomeruli with periglomerular fibrosis. Tubular atrophy was marked in both cortex and medulla, with interstitial fibrosis and cellular infiltration by lymphocytes and occasional plasma cells. In the medulla there was usually alternation of groups of surviving dilated tubules and atrophic tubules in a characteristic radial distribution. The great thickening of the tubular basement membrane, particularly in the distal portion of the nephron, was a prominent feature in all cases. These broad hyaline bands sheathing atrophic tubules were seen in sections stained by haematoxylin and eosin, but were seen most clearly with the periodic acid Schiff (PAS) technique (Fig. 2). The medullary cysts were lined by cubical or flattened epithelial cells. In one case only there was mild chronic inflammation of the pelvis. Hypertensive arteriolar changes of varying severity were present in every case.

In the material from the 3 renal biopsies similar but less severe histological changes were present, though medullary cysts were not identified. Basement membrane thickening associated with atrophic tubules supported the diagnosis of nephronophthisis.

The pathological findings which are of value in diagnosis are summarized in Table IV.

\section{Discussion}

The diagnosis of chronic renal failure associated with small contracted kidneys is seldom difficult, but the classification by cause in the individual patient within this group presents a continuing problem. The original cases described in 1951 by Fanconi et al. recorded a form of chronic nephropathy in 2 unrelated families in whom all 5 sibs in one family and 3 out of the 5 sibs in the other

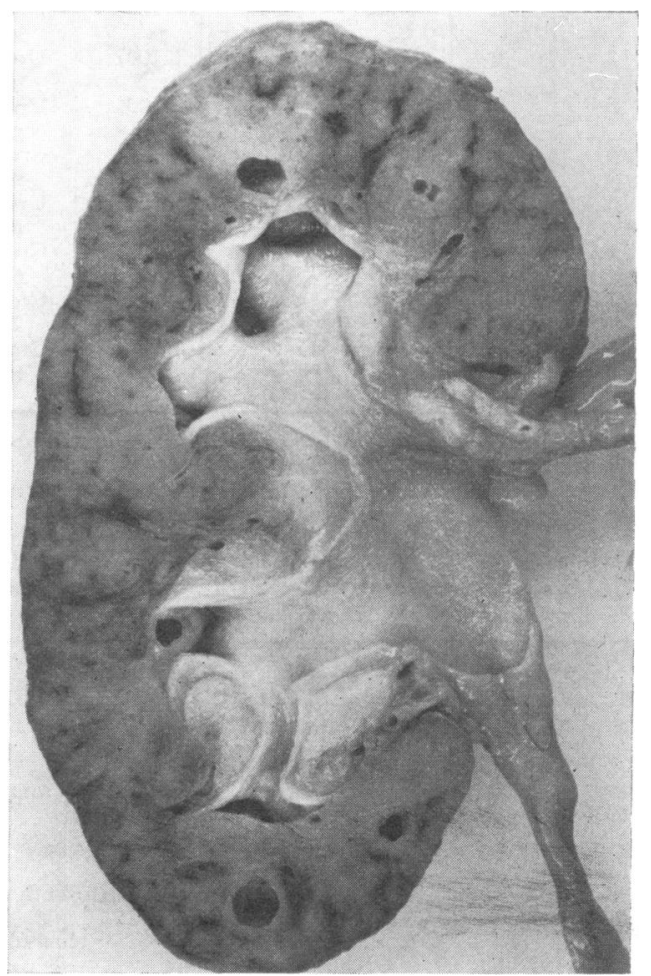

Fig. 1.-Cut surface of the right kidney (Case 6) to show multiple small medullary cysts. $(\times 1 \cdot 5$. 


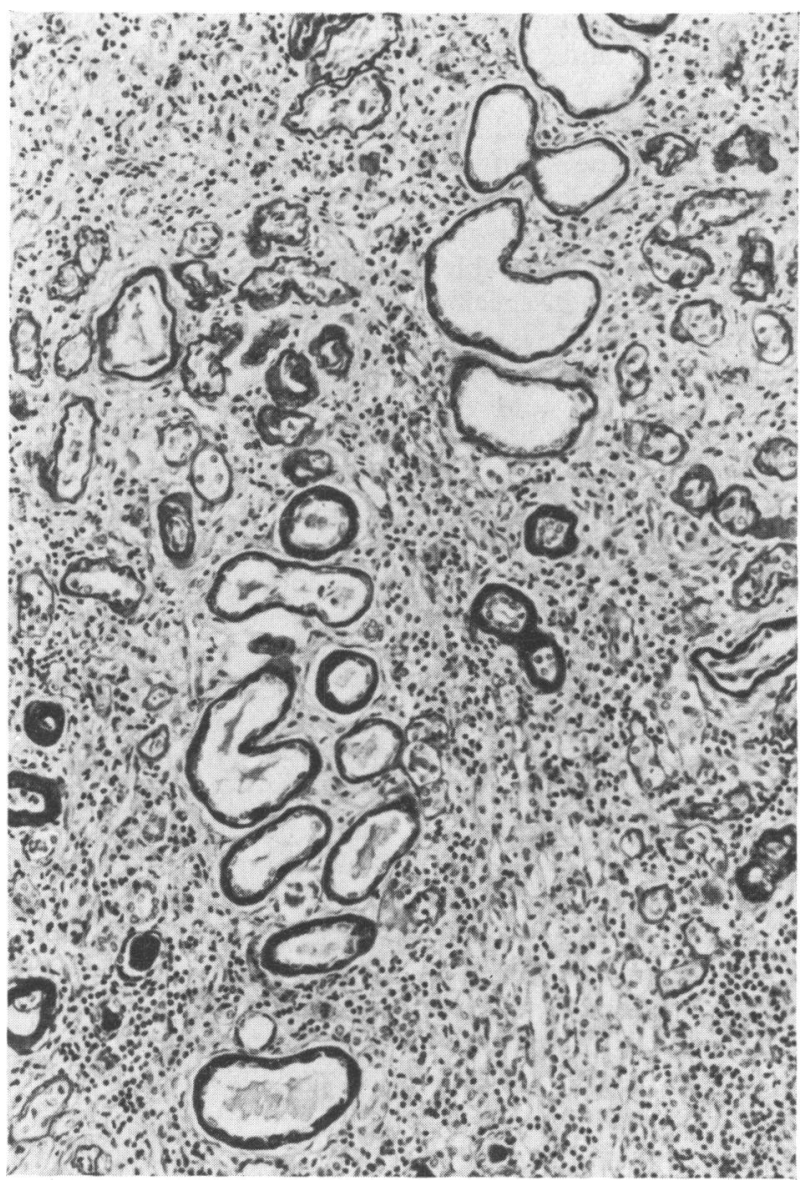

FIG. 2.-Renal medulla (Case 3) to demonstrate marked thickening of the tubular basement membrane, tubular atrophy, and interstitial fibrosis. (P.A.S. $\times 125$.

were affected. The clinical picture was characterized as polyuria, polydipsia, diminished renal concentrating power, raised blood urea, and anaemia. The onset of the disease was usually before 4 years of age, with a progressive course ending in death usually before 10 years of age. The pathological features in the late stages were small contracted kidneys with a loss of differentiation of the renal parenchyma, hyaline degeneration of the glomeruli and the tubular basement membrane, and interstitial fibrosis. Fanconi and his colleagues considered that the condition was primarily a degenerative process rather than the result of inflammation, and they gave it the name of 'familial juvenile nephronophthisis'. Reports from other European centres have confirmed the existence of this new variety of familial nephropathy in children. von Sydow and Ranström (1962) tabulated the details of the cases of nephronopthisis and their sibs from 13 families described in the literature, including their report of a family in which at least 6 of the 11 sibs were affected. Senior, Friedmann, and Braudo (1961) in South Africa described a family of 13 sibs, of whom 6 suffered from nephronophthisis and tapetoretinal degeneration. The first report of familial nephronophthisis in America was described by Mangos et al. (1964).

During this same period a number of reports appeared in the American literature, starting with that of Smith and Graham (1945), of a disease characterized by progressive renal insufficiency and anaemia in which cysts in the renal medulla were a prominent pathological feature. The term 'medullary cystic disease' was applied to this renal condition which became accepted as a clinical and pathological syndrome. It was not until 1964 
that Winberg drew attention to the similarities between medullary cystic disease and familial juvenile nephronophthisis.

These two conditions have been reappraised and there is general agreement that the terminal histology is identical (Strauss and Sommers, 1967; Mongeau and Worthen, 1967). This does not mean that the two names are interchangeable. The term 'medullary cystic disease' is non-specific and probably has a variety of causes. It is misleading in the present context because nephronophthisis affects both cortex and medulla, and the glomerular destruction is probably critical to prognosis. It, therefore, seems to us that the typical clinical appearance in children should be termed juvenile nephronophthisis and modified to familial juvenile nephronophthisis if another sib or relative is similarly affected. Familial incidence was a constant feature of the earlier reports, and there is now general agreement that the condition is inherited as an autosomal recessive character. However, when the family size is limited, as in the present series, the chance of single cases of the disease occurring in a family becomes much greater.

The typical clinical picture is of a dwarfed child aged 4 to 10 years who presents with a story of thirst, polyuria, and a return of nocturnal enuresis. A large bladder is palpable and severe normochromic anaemia present. Haematuria, casturia, and proteinuria are not usually present, and systemic hypertension is a late feature. Renal function is extremely poor and azotaemia with eventual renal osteodystrophy are constant. Hypokalaemia may be present or tapetoretinal degeneration. The various tests of renal function, such as intravenous pyelography and creatinine clearance, reveal in the early stages normal-sized kidneys with a progressive loss of ability to clear and to concentrate. The isosthenic urine is of low specific gravity and osmolality. Tomography will show normal-sized, smooth kidneys in the early stages, and these usually progress to small smooth kidneys with only very fine scarring.

The contracted kidneys associated with chronic renal disease share many pathological features whatever the underlying aetiology, and juvenile nephronophthisis is no exception. Certain points may be of value in distinguishing this particular variety of chronic nephropathy. The appearance of uniformly contracted kidneys with fine scarring of the subcapsular surface reflects the diffuse nature of the disease, and contrasts with the focal involvement of the renal parenchyma and irregular scars which characterize the kidneys in chronic pyelonephritis. The absence of inflammation of the renal pelvis distinguishes nephronophthisis from chronic pyelonephritis. The small medullary cysts, which are a constant finding in our postmortem material and which are present, though not necessarily emphasized, in many of the previous reports of juvenile nephronophthisis, are not a feature of either chronic pyelonephritis or chronic glomerulonephritis, the two conditions with which nephronophthisis is most likely to be confused.

The histological picture of glomerular sclerosis, tubular atrophy, chronic inflammatory infiltration, interstitial fibrosis, and hypertensive arteriolar change is, of course, common to several varieties of chronic renal disease. In nephronophthisis the sclerosis of the glomerular tufts is not associated with much intracapillary or extracapillary proliferation, and in addition periglomerular fibrosis is always prominent in the remaining glomeruli. Tubular atrophy is extensive, but the important feature is the degree of thickening of the basement membrane which is associated with both atrophic and dilated tubules. Though this change is present in the cortex, the distal part of the nephron, particularly the limbs of Henle, is most severely affected. Thickening of the tubular basement membrane is not specific, but if unusually prominent it should suggest the diagnosis of nephronophthisis. The exact nature of the eosinophilic hyaline material which surrounds the tubules is not yet clear; it does not stain for amyloid. The interstitial inflammatory infiltrate is diffuse, mainly lymphocytic in nature, and it is usually mild.

With a typical clinical history, particularly if there is familial involvement, a renal biopsy may provide pathological support for the diagnosis of nephronophthisis. Necropsy will establish it beyond doubt. Four children in this series were diagnosed retrospectively in this way without knowledge of the clinical details.

Little has been added to the understanding of the condition since the original description by Fanconi et al. (1951). There is general acceptance that it is a degenerative rather than an inflammatory process, but there is little information about the histological changes in the early stages of the disease.

The observations of Fetterman, Fabrizio, and Studnicki (1967), employing the technique of microdissection of tubules, may help to throw light on the pathogenesis of the disease. They demonstrated abnormalities in all portions of the nephron, but the most striking finding was the presence of multiple diverticula in approximately $15 \%$ of the descending limbs, which were isolated. This is probably the same lesion which Ivemark, Ljunqvist, and Barry (1960) demonstrated when nephrons 
were filled with radio-opaque material, but which they interpreted as elongation and coiling of the tubule.

We thank our colleagues Professor J. H. Hutchison, and Drs. J. Inall, R. A. Shanks, A. M. MacDonald, and J. D. Briggs for permitting us access to their patients.

\section{REFERENCES}

Alexander, F., and Campbell, S. (1970). Familial uremic medullary cystic disease. Pediatrics, 45, 1024.

Broberger, O., Winberg, J., and Zetterström, R. (1960). Juvenile nephronophthisis. I. A genetically determined nephropathy, with hypotonic polyuria and azotaemia. Acta Paediatrica, 49, 470.

Enell, H. (1952). Two siblings with familial juvenile nephronophthisis. (Swedish.) Nordisk Medicin, 48, 1179.

Fanconi, G., Hanhart, E., von Albertini, A., UUhlinger, E., Dolivo, G., and Prader, A. (1951). Die familiäre juvenile Nephronophthise. Helvetica Paediatrica Acta, 6, 1.

Fetterman, G. H., Fabrizio, N. S., and Studnicki, F. M. (1967). The study by microdissection of structural tubular defects in certain examples of the hereditary nephropathies. In Proceedings of the IIIrd International Congress of Nephrology, Washington, D.C., 1966, vol. 2, p. 235. Karger, Basle and New York.

Hackzell, G. (1952). A case of familial juvenile nephronophthisis. (Abst.) Acta Paediatrica, 41, 607.
Hooft, C., Roels, H., and Herpol, J. (1959). A case of Fanconi's familial juvenile nephronophthisis. Helvetica Paediatrica Acta, 14, 217

Ivemark, B. I., Ljunqvist, A., and Barry, A. (1960). Juvenile nephronophthisis. II. A histologic and İmicroangiographic study. Acta Paediatrica, 49, 480.

Mangos, J. A., Opitz, J. M., Lobeck, C. C., and Cookson, D. U. (1964). Familial juvenile nephronophthisis. Pediatrics, 34, 337.

Mongeau, J. G., and Worthen, H. G. (1967). Nephronophthisis and medullary cystic disease. American fournal of Medicine, 43, 345.

Royer, P., Mathieu, H., and Habib, R. (1963). La néphronophthise héréditaire. In Problèmes Actuels de Néphrologie Infantile, p. 250. Flammarion, Paris.

Senior, B., Friedmann, A. I., and Braudo, J. L. (1961). Juvenile familial nephropathy with tapetoretinal degeneration. American Fournal of Ophthalmology, 52, 625.

Smith, C. H., and Graham, J. B. (1945). Congenital medullary cysts of the kidneys with severe refractory anemia. American fournal of Diseases of Children, 69, 369.

Strauss, M. B., and Sommers, S. C. (1967). Medullary cystic disease and familial juvenile nephronophthisis. New England Journal of Medicine, 277, 863.

von Sydow, G., and Ranström, S. (1962). Familial juvenile nephronophthisis. Acta Paediatrica, 51, 561.

Winberg, J. (1964). Congenital cysts. (Letter to the Editor.) American fournal of Diseases of Children, 108, 566.

Correspondence to Dr. A. A. M. Gibson, Department of Pathology, Royal Hospital for Sick Children, Yorkhill, Glasgow C.3. 